\title{
Evaluation of uterine cervix with transvaginal ultrasonography in women with threatened preterm labor and or preterm labor
}

\author{
Akila Shree, Chitra A. K.* \\ Department of Obstetrics and Gynecology, DSMCH, Siruvachur, Perambalur, Tamil Nadu, India \\ Received: 30 November 2017 \\ Accepted: 08 December 2017 \\ *Correspondence: \\ Dr. Chitra A. K., \\ E-mail: chithraak82@gmail.com \\ Copyright: (C) the author(s), publisher and licensee Medip Academy. This is an open-access article distributed under \\ the terms of the Creative Commons Attribution Non-Commercial License, which permits unrestricted non-commercial \\ use, distribution, and reproduction in any medium, provided the original work is properly cited.
}

\begin{abstract}
Background: Preterm delivery can be associated with substantial perinatal morbidity and mortality. Nearly in 5 to $13 \%$ of pregnancies, happening deliveries are preterm before 37 weeks' gestation. Thus, prediction of preterm labor in parturient can provide a window of opportunity to prevent these complications and to be better prepared to deal with them. Hence the current study has been conducted with an objective to assess the efficiency of cervical length and funneling as assessed by transvaginal ultrasonography in predicting preterm labor.

Methods: The current study was a prospective study, conducted in the Department of Obstetrics Emergencies, Dhanalakshmi Srinivasan Medical College and Hospital between November 2015 to April 2017. The study population included 60 women with singleton pregnancy of gestational age between $28+0$ and $36+6$ weeks and with painful and regular contractions (>1/10 min for at least 1 hour). Cervical length, funnelling length measured at presentation and after 48 hours were considered as predictor variables. The outcomes of interest were delivery within 1 week, delivery before 37 weeks and delivery before 34 weeks.

Results: There was a statistically significant difference in cervical length and funnelling length between term and preterm groups at the time of diagnosis and after 48 hours $(\mathrm{P}<0.001)$. The positive predictive value increased from $33.3 \%$ to $100 \%$ with cervical length $\leq 40 \mathrm{~mm}$ to $\leq 20 \mathrm{~mm}$. The negative predictive value decreased from $100 \%$ to $79.2 \%$ with cervical length $\leq 40 \mathrm{~mm}$ to $\leq 20 \mathrm{~mm}$. To predict a preterm delivery in threatened preterm delivery patients, the sensitivity of a cervical length of $\leq 25 \mathrm{~mm}$ was $77.7 \%$, specificity was $95.2 \%$, the positive predictive value was $87.5 \%$ and negative predictive value is $90.9 \%$.

Conclusions: Cervical length and funnelling as assessed by transvaginal ultrasonography are efficient in predicting preterm labor.
\end{abstract}

Keywords: Cervical length, Funneling length, Preterm delivery, Transvaginal ultrasonography

\section{INTRODUCTION}

Nearly in 5 to $13 \%$ of pregnancies, happening deliveries are preterm before 37 weeks' gestation. Perinatal morbidity and mortality are mostly caused by preterm delivery. ${ }^{1,2}$ Basically, the exact mechanism behind preterm labor was not yet known clearly. However preterm deliveries may cause decidual hemorrhage, cervical incompetence, Mullerian duct abnormalities, fibroid uterus, cervical inflammation, hormonal changes, and uteroplacental insufficiency. uterine activity and cervical dilation result in the cascade of events which are underlying. ${ }^{3-6}$

To evaluate the risk of preterm birth was usually done by measuring the cervical length and detecting cervical funneling. Clinical diagnosis of preterm labor is unreliable because it is very subjective. ${ }^{7,8}$ In general, 
clinical practice transvaginal ultrasound is being used to investigate the risk of preterm deliveries because of its accuracy for predicting preterm delivery than manual examination. ${ }^{9,10}$ Even though transabdominal sonographic evaluation can give good interobserver reliability, because of few technical difficulties of this technique makes the transvaginal ultrasonography as the better choice for assessing cervical measurements. ${ }^{11,12}$

Clear and consistently successful visualization of the cervix and internal organs is allowed by Transvaginal ultrasound which makes it as more advantageous than transabdominal sonographic evaluation. Thus, in women undergoing preterm labor, prediction of preterm delivery is done efficiently by transvaginal ultrasonography. ${ }^{13-16}$ The cut-off limits proposed by each author were not shown reliable in any other sample than the initial one because of small sample size. To fill this gap current study was conducted with the aim of examination of the relationship between cervical length, funnelling and risk of preterm delivery with transvaginal ultrasonography in threatened preterm labor.

\section{METHODS}

This prospective study included women who presented with symptoms of preterm labor at Obstetric Emergencies of DSMCH, between November 2015 and April 2017. The women presenting with a singleton pregnancy, with gestational age between $28+0$ and $36+6$ weeks and Painful and regular contractions $(>1 / 10$ minutes for at least 1 hour) were included in the study.

Women with multiple pregnancies, women in active labour (cervical dilation $>3 \mathrm{~cm}$ ), evidence of preterm rupture of membranes, history of cervical incompetence with cerclage, presence of chorioamnionitis, abnormal nonstress test before tocolysis, placenta praevia, abruptio placenta, hydramnios, intrauterine growth restriction, preeclampsia or gestational hypertension and presence of any other maternal and/or foetal pathology mandating preterm delivery were the exclusion criteria used in the study.

In the event of women presenting with symptoms twice during their pregnancy, they were only included in the study at their first admission.

The study was approved by the Bioethics Committee and informed consent was obtained from all participants. Recorded parameters included cervical length at presentation and 48 hours later, gestational age at presentation and birth, maternal age, parity and previous history of preterm birth.

Cervical length was measured at presentation. After women were asked to empty their bladder, a transvaginal probe was placed in the anterior fornix, a sagittal view of the cervix was obtained, and the length (mm) of the echogenic cervical canal was measured over a period of 3 min and funneling if present its length (mm) measured. ${ }^{12}$ The shortest measurement was recorded. A second measurement was repeated after $48 \mathrm{~h}$ using the same methodology. During a uterine contraction, the procedure was withheld until the end of the contraction. The outcomes of interest were delivery within 1 week, delivery before 37 weeks and delivery before 34 weeks. The reported interobserver and intraobserver variability of ultrasound measurement of cervical length is approximately $10 \%{ }^{8}$

After admission, tocolysis was given. Betamethasone 12 mg was given and repeated after 24 hours. The patient kept under supervision for one week. Cervical length was again measured after 48 hours by transvaginal ultrasonography. The result of the two-transvaginal ultrasonography measurement was not disclosed to the obstetric team and, therefore, did not influence subsequent patient management.

Women were then discharged and subsequently followed up as outpatients unless there was a recurrence of uterine contractions. Statistical analysis was conducted by comparing the mean values of the outcome parameters between preterm and normal women using independent sample-test. Categorical variables were compared between two groups by Chi square test. IBM SPSS version 21 was used for statistical analysis. ${ }^{15}$

\section{RESULTS}

Among the study participants, the mean age of all patients was 24.18 years and mean gestational age at presentation was 31.95 weeks. Mean duration of symptoms before seeking medical care in all patients in this study was 5.30 hours.

Table 1: Characteristics of the study population $(\mathrm{N}=60)$.

\begin{tabular}{|ll|}
\hline Characteristic & Summary \\
\hline Age $($ Mean \pm SD) & $24.18 \pm 2.76$ \\
\hline Gestational age (weeks) (Mean \pm SD) & $31.95 \pm 2.25$ \\
\hline Duration of symptoms (Mean \pm SD) (hours) & $5.30 \pm 4.09$ \\
\hline Age group (N, \%) & \\
\hline $19-21$ & $10(16.7 \%)$ \\
\hline $22-24$ & $26(43.3 \%)$ \\
\hline $25-27$ & $16(26.6 \%)$ \\
\hline $28-32$ & $8(13.3 \%)$ \\
\hline Parity $(\mathbf{N}, \%)$ & \\
\hline Primigravida & $21(35 \%)$ \\
\hline Multigravida & $39(65 \%)$ \\
\hline Past obstetric history (N, \%) & $16(26.6 \%)$ \\
\hline $1^{\text {st }}$ trimester abortion in the past & $4(6.6 \%)$ \\
\hline $2^{\text {nd }}$ trimester abortion in the past & $14(23.3 \%)$ \\
\hline H/o preterm & \\
\hline Outcome $(\mathbf{N}, \%)$ & $18(30 \%)$ \\
\hline Preterm & $42(70 \%)$ \\
\hline Term
\end{tabular}


Among the study population, the number of study participants in 19 to 21year age group was $10(16.7 \%)$. The number of people in 22 to 24,25 to 27 and 28 to 32 year age groups was $26(43.3 \%), 16(26.6 \%)$ and 8 $(13.3 \%)$ respectively. The number of participants with primigravida was $21(35 \%)$ and multigravida were 39 (65\%). Among the study participants, the proportion of 1 st-trimester abortion in the past was $26.6 \%, 2^{\text {nd }}$ trimester abortion in the past was $6.6 \%$ and the proportion of $\mathrm{H} / \mathrm{O}$ preterm was $23.3 \%$. Among the study participants, the proportion of preterm deliveries was $30 \%$ and remaining $70 \%$ were term deliveries (Table 1 ).

Among the study participants Mean age of patients in preterm group was 23.44 years and term group were 24.5 years. Mean gestational age at presentation in preterm group was 32.05 weeks and term group were 31.09 weeks.

Mean duration of symptoms in the preterm group is 5.44 hours and term group is 5.24 hours. The mean difference of age, gestational age, and duration of symptoms between preterm and term groups were statistically not significant.

In preterm group 7 patients $(38.9 \%)$ were primigravida and 11 patients $(61.1 \%)$ were multigravida. In term group 14 patients $(33.3 \%)$ were primigravida and 28 patients $(66.7 \%)$ were multigravida.

Preterm group patients with the previous history of abortion in the first trimester were $5(16.6 \%)$ and in the second trimester was $1(5.55 \%)$. Term group patients with the previous history of abortion in the first trimester were $11(26.1 \%)$ and in the second trimester was 3 $(7.14 \%)$. The difference between the two groups in terms of history of abortions, primigravida, and multigravida was statistically not significant

Preterm group patients with the previous history of preterm delivery were $(44.5 \%)$. Term group patients with the previous history of preterm delivery were $6(14.3 \%)$. The difference in the history of preterm delivery is significant $(\mathrm{P}=0.0395)$ between the two groups.

Mean cervical length of the preterm group at the time of diagnosis and after 48 hours is $22.17 \mathrm{~mm}$ and $22.50 \mathrm{~mm}$ and in term group patients it is 36.14 and 36.71 respectively. Mean difference between preterm and term groups was statistically significant $(\mathrm{P}<0.001)$.

Mean funneling length in the preterm group at the time of diagnosis of threatened preterm labor and after 48 hours of tocolysis is $6.94 \mathrm{~mm}$ and $8.35 \mathrm{~mm}$ respectively and in term group patients is $2.26 \mathrm{~mm}$ and $2.23 \mathrm{~mm}$ respectively. Mean difference between preterm and term groups was statistically significant $(\mathrm{P}<0.001)$ (Table 2$)$.

The positive predictive value increased from $33.3 \%$ to $100 \%$ with cervical length $\leq 40 \mathrm{~mm}$ to $\leq 20 \mathrm{~mm}$. The negative predictive value decreased from $100 \%$ to $79.2 \%$ with cervical length $\leq 40 \mathrm{~mm}$ to $\leq 20 \mathrm{~mm}$. To predict a preterm delivery in threatened preterm delivery patients, sensitivity of a cervical length of $\leq 25 \mathrm{~mm}$ was $77.7 \%$, specificity was $95.2 \%$, positive predictive value was $87.5 \%$ and negative predictive value is $90.9 \%$ (Table 3 ).

Table 2: Comparison of various clinical and transvaginal ultra-sonographic parameters between preterm and term deliveries.

\begin{tabular}{|c|c|c|c|}
\hline $\begin{array}{l}\text { Clinical } \\
\text { characteristics }\end{array}$ & Preterm & Term & $\begin{array}{l}P \\
\text { value }\end{array}$ \\
\hline $\begin{array}{l}\text { Age (years) } \\
(\text { Mean } \pm \text { SD) }\end{array}$ & $23.44 \pm 3.04$ & $24.5 \pm 2.79$ & 0.6211 \\
\hline $\begin{array}{l}\text { Gestational age } \\
\text { (Weeks) } \\
(\text { Mean } \pm \text { SD) }\end{array}$ & $32.05 \pm 2.31$ & $31.90 \pm 2.25$ & 0.4469 \\
\hline $\begin{array}{l}\text { Duration of } \\
\text { symptoms } \\
\text { (Mean } \pm \mathrm{SD}) \\
\text { (hours) }\end{array}$ & $5.44 \pm 4.78$ & $5.24 \pm 3.82$ & 0.9611 \\
\hline $\begin{array}{l}\text { Primigravida } \\
(\mathrm{N}, \%)\end{array}$ & $7(38.9 \%)$ & $14(33.3 \%)$ & 0.9100 \\
\hline $\begin{array}{l}\text { Multigravida } \\
(\mathrm{N}, \%)\end{array}$ & $11(61.1 \%)$ & $28(66.7 \%)$ & 0.8523 \\
\hline $\begin{array}{l}1^{\text {st }} \text { Trimester } \\
\text { abortion in the } \\
\text { past }(N, \%)\end{array}$ & $5(27.7 \%)$ & $11(26.1 \%)$ & 0.865 \\
\hline $\begin{array}{l}2^{\text {nd }} \text { Trimester } \\
\text { abortion in the } \\
\text { past }(N, \%)\end{array}$ & $1(5.55 \%)$ & $3(7.14 \%)$ & 0.442 \\
\hline $\begin{array}{l}\text { H/o Preterm } \\
(\mathrm{N}, \%)\end{array}$ & $8(44.5 \%)$ & $6(14.3 \%)$ & 0.0395 \\
\hline $\begin{array}{l}\text { Cervical length a } \\
\text { diagnosis } \\
(\text { Mean } \pm \text { SD) }\end{array}$ & $22.17 \pm 5.75$ & $36.14 \pm 5.31$ & $<0.001$ \\
\hline $\begin{array}{l}\text { Cervical length } \\
\text { at } 48 \\
\text { hours (Mean } \\
\pm \text { SD) }\end{array}$ & $22.50 \pm 4.35$ & $36.71 \pm 5.45$ & $<0.001$ \\
\hline $\begin{array}{l}\text { Mean funnel } \\
\text { length at } \\
\text { admission } \\
\text { (Mean } \pm \text { SD) }\end{array}$ & $6.94 \pm 2.70$ & $2.26 \pm 2.24$ & $<0.001$ \\
\hline $\begin{array}{l}\text { Mean funnel } \\
\text { length at } 48 \\
\text { hours } \\
(\text { Mean } \pm \text { SD) }\end{array}$ & $8.35 \pm 2.21$ & $2.23 \pm 2.25$ & $<0.001$ \\
\hline
\end{tabular}

The positive predictive value decreased from $72.7 \%$ (CL1 $\leq 30)$ to $63.63 \%$ (CL1 $\leq 30+$ change $>20 \%$ ) and from $100 \%$ (CL1 $\leq 20)$ to $71.4 \%$ (CL1 $\leq 20+$ change $>20 \%$ ) when cervical length at diagnosis is combined with $20 \%$ change in $2^{\text {nd }}$ ultrasound. Negative predictive value decreased from 94.7 (CL1 $\leq 30$ ) to $77.55 \%$ (CL1 $\leq 30+$ change $>20 \%$ ) and from 79.2 (CL1 $\leq 20$ ) to $75.5 \%$ $(\mathrm{CL} 1 \leq 20+$ change $>20 \%)$ when cervical length at diagnosis is combined with $20 \%$ change in 2 nd ultrasound (Table 4). 
Table 3: Predictable value of cervical length in preterm delivery.

\begin{tabular}{|c|c|c|c|c|c|c|}
\hline $\begin{array}{l}\text { Cervical length at } \\
\text { diagnosis }(\mathrm{mm})\end{array}$ & $\begin{array}{l}\text { Preterm delivery } \\
(\mathrm{n}=18)\end{array}$ & Term delivery ( $n=42$ ) & Sensitivity & specificity & PPV & NPV \\
\hline$>40$ & 0 & 8 & - & - & - & $100 \%$ \\
\hline$\leq 40$ & 18 & 36 & $100 \%$ & $18.8 \%$ & $33.3 \%$ & - \\
\hline$>35$ & 0 & 25 & - & - & - & $100 \%$ \\
\hline$\leq 35$ & 18 & 17 & $100 \%$ & $59.52 \%$ & $62.2 \%$ & - \\
\hline$>30$ & 2 & 36 & - & - & - & $94.73 \%$ \\
\hline$\leq 30$ & 16 & 6 & $88.8 \%$ & $85.71 \%$ & $72.7 \%$ & - \\
\hline$>25$ & 4 & 40 & - & - & - & $90.9 \%$ \\
\hline$\leq 25$ & 14 & 2 & $77.7 \%$ & $95.2 \%$ & $87.5 \%$ & - \\
\hline$>20$ & 11 & 42 & - & - & - & $79.2 \%$ \\
\hline$\leq 20$ & 7 & 0 & $38.3 \%$ & $100 \%$ & $100 \%$ & - \\
\hline
\end{tabular}

Table 4: Significance of $2^{\text {nd }}$ transvaginal ultrasound.

\begin{tabular}{|c|c|c|c|c|c|c|}
\hline $\begin{array}{l}\text { Test cut-off } \\
\text { Value }\end{array}$ & $\begin{array}{l}\text { Preterm delivery } \\
(\mathrm{n}=\mathbf{1 8})\end{array}$ & $\begin{array}{l}\text { Term delivery } \\
(n=42)\end{array}$ & $\begin{array}{l}\text { Sensitivity } \\
\mathrm{n} / \mathrm{N}, \%\end{array}$ & $\begin{array}{l}\text { specificity } \\
\mathrm{n} / \mathrm{N}, \%\end{array}$ & $\begin{array}{l}\text { PPV n/N, } \\
\%\end{array}$ & $\begin{array}{l}\text { NPV n/N, } \\
\%\end{array}$ \\
\hline \multirow[t]{2}{*}{ CL1 $\leq 30$} & 16 & 6 & $16 / 18$ & $36 / 42$ & $16 / 22$ & $36 / 38$ \\
\hline & 2 & 36 & $88.8 \%$ & $85.71 \%$ & $72.7 \%$ & $94.7 \%$ \\
\hline \multirow[t]{2}{*}{ CL1 $\leq 20$} & 7 & 0 & $7 / 18$ & $42 / 42$ & $7 / 7$ & $42 / 53$ \\
\hline & 11 & 42 & $38.3 \%$ & $100 \%$ & $100 \%$ & $79.2 \%$ \\
\hline \multirow[t]{2}{*}{ CL change $>20 \%$} & 6 & 7 & $6 / 18$ & $35 / 42$ & $6 / 13$ & $35 / 47$ \\
\hline & 12 & 35 & $33.3 \%$ & $83.3 \%$ & $46.1 \%$ & $74.46 \%$ \\
\hline \multirow[t]{3}{*}{ CL1 $\leq 30+$ change $>20 \%$} & 7 & 4 & $7 / 18$ & $38 / 42$ & $7 / 11$ & $38 / 49$ \\
\hline & 11 & 38 & $38.88 \%$ & $90.47 \%$ & $63.63 \%$ & $77.55 \%$ \\
\hline & 5 & 2 & $5 / 18$ & $40 / 42$ & $5 / 7$ & $40 / 53$ \\
\hline CL1 $\leq 20+$ change $>20 \%$ & 13 & 40 & $27.7 \%$ & $95.2 \%$ & $71.4 \%$ & $75.5 \%$ \\
\hline
\end{tabular}

\section{DISCUSSION}

Risk of preterm delivery was associated with the shortening of Cervical length or effacement. ${ }^{16}$ Evaluation of cervix was more accurate and advantageous by Transvaginal ultrasonography than manual evaluation and trans abdominal evaluation. Few studies have attempted to evaluate its usefulness as a predictor of risk of preterm delivery. ${ }^{17-20}$ The current study focused on the evaluation of uterine cervix with transvaginal ultrasonography in women with threatened preterm labor and/or preterm labor.

Among the study participants, the mean age of all patients was 24.18 years and mean gestational age at presentation was 31.95 weeks. Mean duration of symptoms before seeking medical care in all patients in this study was 5.30 hours. Similarly, Tongsong $\mathrm{T}$ et al recruited 730 women with mean age of $27.22 .{ }^{17}$

In the current study among the study participants the proportion of preterm deliveries was $30 \%$ and remaining $70 \%$ were term deliveries. Similarly, In Murakawa et al (1993) 13 study reported 33\% were preterm delivery and in Rozenberg et alstudy $41.3 \%$ were preterm delivery. ${ }^{14}$ A study by Vendittelli $\mathrm{F}$ et al shows the incidence of preterm deliveries was $41 \% .{ }^{18}$
In the present study mean gestational age at presentation in preterm group was 32.05 weeks and term group were 31.09 weeks. The mean difference between two groups was statistically not significant. Like this study, Murakawa et al have shown that the mean gestational age at diagnosis in patients, delivered preterm was 31.6 weeks and the term was 30.6 weeks. ${ }^{13}$ Rozenberg et al have reported that the mean gestational age in the preterm delivery group was 29 weeks and the term delivery group was 30 weeks which is statistically not significant. ${ }^{14}$

In current study mean cervical length of the preterm group at the time of diagnosis and after 48 hours is 22.17 $\mathrm{mm}$ and $22.50 \mathrm{~mm}$ and in term group patients it is 36.14 and 36.71 respectively. Mean difference between preterm and term groups was statistically significant $(\mathrm{P}<0.001)$ Like our study in patients diagnosed to have threatened preterm labor, Anderson et al on transvaginal ultrasonography found the mean cervical length to be shorter amongst patients who delivered preterm (34.1 $\mathrm{mm})$ in comparison to patients who delivered at term $(42.8 \mathrm{~mm}){ }^{21}$ Murakawa et al found that in term delivery patient's, the cervical length remained normal range (31.7 $\mathrm{mm})$ and in preterm delivery patients the cervical length was shorter than the normal range $(23.2 \mathrm{~mm}) .{ }^{13}$ Rozenberg et al found that in term delivery patient's, the cervical length remained normal range $(20 \mathrm{~mm})$ and in preterm delivery patients the cervical length was shorter 
than the normal range $(16 \mathrm{~mm}) .{ }^{14}$ Like this study, study of Tongsong $\mathrm{T}$, et al, reported less mean cervical length $(34 \mathrm{~mm})$ in preterm group than term group $(37 \mathrm{~mm}) .{ }^{17}$

In the present study, a cervical length of less than $20 \mathrm{~mm}$ on admission had a positive predictive value of $100 \%$ for preterm delivery. The negative predictive value was $94.73 \%$ in women whose cervical length was $30 \mathrm{~mm}$ or more, the sensitivity of cervical length less than $30 \mathrm{~mm}$ was $88.8 \%$ and specificity was $85.71 \%$. In literature few other studies also assessed the predictive value of cervical length was evaluated by transvaginal ultrasonography on admission in patients with normal pregnancy and threatened preterm labor (Murakawa et al, Vendittelli $\mathrm{F}$ et al). ${ }^{22,13,18}$

In Murakawa et al study a cervical length of less than 20 $\mathrm{mm}$ on admission had a positive predictive value of $100 \% .^{13}$ These patients had preterm deliveries despite tocolytic therapy during hospitalization. The negative predictive value was $100 \%$ in women whose cervical length was $30 \mathrm{~mm}$. the sensitivity of cervical length less than $30 \mathrm{~mm}$ was $100 \%$ and specificity was $71.4 \%$.

Like this study, Vendittelli $\mathrm{F}$ et al study findings shows that cervical length of less than $30 \mathrm{~mm}$ had a sensitivity of $0.83,95 \%$ (CI 0.78 ) 0.88 ; a specificity of $0.50,95 \% \mathrm{CI}$ $0.48,0.57$, a positive predictive value PPV of $0.54,95 \%$ CI $0.47,0.60$, and a negative predictive value NPV of $0.80,95 \%$ CI $0.75,0.86{ }^{18}$

The positive predictive value decreased from $72.7 \%$ (CL1 $\leq 30)$ to $63.63 \%$ (CL1 $\leq 30+$ change $>20 \%$ ) and from $100 \%(\mathrm{CL} 1 \leq 20)$ to $71.4 \%$ (CL1 $\leq 20+$ change $>20 \%)$ when cervical length at diagnosis is combined with $20 \%$ change in $2^{\text {nd }}$ ultrasound. Negative predictive value decreased from 94.7 (CL1 $\leq 30)$ to $77.55 \%$ (CL1 $\leq 30+$ change $>20 \%)$ and from $79.2(\mathrm{CL} 1 \leq 20)$ to $75.5 \%$ (CL1 $\leq 20+$ change $>20 \%$ ) when cervical length at diagnosis is combined with $20 \%$ change in $2^{\text {nd }}$ ultrasound.

\section{CONCLUSION}

Cervical length and funnelling as assessed by transvaginal ultrasonography are efficient in predicting preterm labor.

\section{Funding: No funding sources}

Conflict of interest: None declared

Ethical approval: The study was approved by the Institutional Ethics Committee

\section{REFERENCES}

1. Barber MA, Eguiluz I, Plasencia W, Medina M, Valle L, Garcia JA. Preterm delivery and ultrasound measurement of cervical length in Gran Canaria, Spain. Int J Gynaecol Obstet. 2010;108(1):58-60.

2. Martin JA, Osterman MJ, Sutton PD. Are preterm births on the decline in the United States? Recent data from the National Vital Statistics System. NCHS Data Brief. 2010(39):1-8.

3. Iams JD, Berghella V. Care for women with prior preterm birth. Am J Obstet Gynecol. 2010;203(2):89-100.

4. Peltier MR. Immunology of term and preterm labor. Reprod Biol Endocrinol. 2003;1:122.

5. Rackow BW, Arici A. Reproductive performance of women with Mullerian anomalies. Curr Opin Obstet Gynecol. 2007;19(3):229-37.

6. Celik E, To M, Gajewska K, Smith GC, Nicolaides $\mathrm{KH}$. Cervical length and obstetric history predict spontaneous preterm birth: development and validation of a model to provide an individualized risk assessment. Ultrasound Obstet Gynecol. 2008;31(5):549-54.

7. Herbst A, Nilsson C. Diagnosis of early preterm labor. BJOG. 2006;113(3):60-7.

8. Iams JD, Goldenberg RL, Meis PJ, Mercer BM, Moawad A, Das A, et al. The length of the cervix and the risk of spontaneous premature delivery. National Institute of child health and human development maternal-fetal medicine unit network. N Engl J Med. 1996;334(9):567-72.

9. Gomez R, Galasso M, Romero R, Mazor M, Sorokin $\mathrm{Y}$, Goncalves L, et al. Ultrasonographic examination of the uterine cervix is better than cervical digital examination as a predictor of the likelihood of premature delivery in patients with preterm labor and intact membranes. Am J Obstet Gynecol. 1994;171(4):956-64.

10. Sonek JD, Iams JD, Blumenfeld $\mathrm{M}$, Johnson $\mathrm{F}$, Landon M, Gabbe S. Measurement of cervical length in pregnancy: comparison between vaginal ultrasonography and digital examination. Obstet Gynecol. 1990;76(2):172-5.

11. Andersen HF. Transvaginal and transabdominal ultrasonography of the uterine cervix during pregnancy. J Clin Ultrasound. 1991;19(2):77-83.

12. Burger $M$, Weber-Rossler $T$, Willmann $M$. Measurement of the pregnant cervix by transvaginal sonography: an interobserver study and new standards to improve the interobserver variability. Ultrasound Obstet Gynecol. 1997;9(3):188-93.

13. Murakawa H, Utumi T, Hasegawa I, Tanaka K, Fuzimori R. Evaluation of threatened preterm delivery by transvaginal ultrasonographic measurement of cervical length. Obstet Gynecol. 1993;82(5):829-32.

14. Rozenberg P, Goffinet F, Malagrida L, Giudicelli Y, Perdu M, Houssin I, et al. Evaluating the risk of preterm delivery: a comparison of fetal fibronectin and transvaginal ultrasonographic measurement of cervical length. Am J Obstet Gynecol. 1997;176(1):196-9.

15. IBM Corp. Released 2013. IBM SPSS Statistics for Windows, Version 22.0. Armonk, NY: IBM Corp.

16. Okitsu O, Mimura T, Nakayama T, Aono T. Early prediction of preterm delivery by transvaginal 
ultrasonography. Ultrasound Obstet Gynecol. 1992;2(6):402-9.

17. Tongsong $\mathrm{T}$, Kamprapanth $\mathrm{P}$, Srisomboon J, Wanapirak C, Piyamongkol W, Sirichotiyakul S. Single transvaginal sonographic measurement of cervical length early in the third trimester as a predictor of preterm delivery. Obstet Gynecol. 1995;86(2):184-7.

18. Vendittelli F, Mamelle N, Munoz F, Janky E. Transvaginal ultrasonography of the uterine cervix in hospitalized women with preterm labor. Int $\mathbf{J}$ Gynaecol Obstet. 2001;72(2):117-25.

19. Arisoy R, Yayla M. Transvaginal sonographic evaluation of the cervix in asymptomatic singleton pregnancy and management options in short cervix. J Pregnancy. 2012;2012:201628.

20. Honest H, Bachmann LM, Coomarasamy A, Gupta JK, Kleijnen J, Khan KS. The accuracy of cervical transvaginal sonography in predicting preterm birth: a systematic review. Ultrasound Obstet Gynecol. 2003;22(3):305-22.

21. Andersen HF, Nugent CE, Wanty SD, Hayashi RH. Prediction of risk for preterm delivery by ultrasonographic measurement of cervical length. Am J Obstet Gynecol. 1990;163(3):859-67.

22. Ayers JW, De Grood RM, Compton AA, Barclay M, Ansbacher R. Sonographic evaluation of cervical length in pregnancy: diagnosis and management of preterm cervical effacement in patients at risk for premature delivery. Obstet Gynecol. 1988;71(6):93944.

Cite this article as: Shree A, Chitra AK. Evaluation of uterine cervix with transvaginal ultrasonography in women with threatened preterm labor and or preterm labor. Int J Reprod Contracept Obstet Gynecol 2018;7:704-9. 